\title{
PENGARUH LABEL HALAL DAN CELEBRITY ENDORSERTERHADAP KEPUTUSAN PEMBELIAN (Studi Kasus pada Pelanggan Kosmetik Wardah di Kota Sumbawa )
}

\author{
${ }^{1}$ Indri Afriliantini, ${ }^{2}$ Abdul Salam, ${ }^{3}$ Abdurrahman \\ Mahasiswa Fakultas Ekonomi Dan Bisnis Universitas Teknologi Sumbawa \\ Dosen Fakultas Ekonomi Dan Bisnis Universitas Teknologi Sumbawa \\ Fakultas Ekonomi dan Bisnis Universitas Teknologi Sumbawa \\ Email: indriapriliantii22@gmail.com \\ abdul.salam@uts.ac.id. \\ abdurrahman@uts.ac.id.
}

Decision

\begin{abstract}
Diterima
Bulan juli 2019

Diterbitkan

Bulan juli 2019

Keywords: Label

Halal, Celebrity

Endorser, and

Purchasing

\section{Abstrak}

The purpose this study is to determine : 1) Effect of halal labels on wardah cosmetic purchasing decision. 2) Effect of celebrity endorser on purcahasing decisions. The model used in data analysis is the research instrumens, classic assumption test, multiple linear analysis, and test the hypothesis. The analytical tool used in this study is SPSS 16. Data used is primary data and secondary data with sampling purposive sampling. The result of this study show 1) label halal label has a positive and significant what is indicated by the value for the halal label variabel is equal to 0.000 where is this value $<0,5.2)$ celebrity endorser have a positive and significant shown by the value for the celebrity endorser variable value is equal to 0.014 where is this value > dari 0,5.
\end{abstract}

\section{PENDAHULUAN}

Pertumbuhan penduduk muslim dunia semakin hari semakin bertambah, hal ini terlihat dari meningkatnya perminatan produk halal oleh beberapa negara dibelahan dunia. Produk dengan kehalalan yang terjamin dan disertifikasi oleh lembaga penjaminan nasional maupun internasional, saat ini menjadi prioritas utama masyarakat muslim khususnya, terlihat dari tren konsumen dalam membeli produk yang bersertifikasi halal pada kemasannya. Hal ini terlihat pada pertumbuhan permintan produk halal dunia meningkat sebanyak $6,19 \%$ dalam kurun waktu 2013 sampai dengan 2018

(www.sindonews.com, 2019).

Tren produk halal tersebut tidak hanya masuk dalam pasar dunia, khususnya pasar Indonesia juga sedang gencar-gencarnya para konsumen melihat sertifikasi halal produk sebelum memutuskan membeli sebuah produk. (www.sindonews.com, 2019).

Kehalalan akan menjadi penting dalam kajian pemasaran di Indonesia, karena saa ini konsumen akan memperhatikan label halal yang tertera pada produk yang diperjual belikan pada pasar. Ummat muslim percaya bahwa dengan mengkonsumsi makanan yang halal akan menjadi berkah dan sehat untuk manusia. Kehalalan merupakan pokok utama bagi umat muslim untuk beribadah agar senantiasa manusia selalu dijalan yang benar, disamping itu kehalalan tertera dalam hadist dan Alquran. Islam mengajarkan kita agar senantiasa untuk mengkonsumsi yang ada dimuka bumi yang serba halal dan baik, baik makanan dan minuman bahkan selain itu seperti kosmetik, obat-obatan dan lain-lainnya. Kosmetik dan obat-obatan keduannya disebut halal apabila bahan-bahan yang terkdanung dalam keduanya harus dari bahan baku pilihan yang sesuai syariat Islam dan memiliki sertifikat halal dari Majelis Ulama Indonesia (www.halalmui.org, 2019).

Konsep halal dalam kehidupan masyarakat Indonesia telah banyak dikenal dan diterapkan khususnya umat Islam. Halal diperuntukkan bagi segala sesuatu yang baik dan bersih yang dimakan atau dikonsumsi oleh manusia menurut syari'at Islam. Allah telah menegaskan dalam Al-quran surat $\mathrm{Al}$-maidah ayat 3: "Diharamkan bagimu (memakan) bangkai, darah, daging babi" (QS.5:3). Menurut ayat diatas, kata "memakan" tidak hanya dimaksudkan memakan melalui mulut, tetapi memakan tersebut dapat berarti mengkonsumsi dalam menggunakan olahan babi untuk berbagai

keperluan termasuk kosmetik. Selainitu pada alqur'an surah Al-Nahl ayat 114 juga dijelaskan : 
“ Maka makanlah yang halal lagi baik dari rezeki yang telah diberikan allah kepadamu; dan syukurilah nikmat Allah jika

kamu hanya kepada-Nya saja menyembah". (QS.16:114). Pada surat Al-Nahl ayat 114 tersebut dijelaskan bahwa Allah memerintah kepada manusia untuk memakan (mengkonsumsi) makan yang halal, hal ini dapat dianalogikan pada produk selain makanan yang dikonsumsi konsumen muslim termasuk kosmetik dan perawatan kulit.

Indonesia yang memiliki penduduk muslim terbesar didunia memliki permintaan akan produk halal lebih besar dari pada negaranegara di dunia lainnya, hal ini terlihat pada kebijakan pemerintah Indonesia yang mulai memperkuat sistem standar produk yang beredar di Indonesia dan juga terlihat dari banyknya produk yang tidak memiliki sertifikasi halal resmi yang dilarang peredarannya oleh pemerintah di Indonesia. Produk halal yang diminati oleh penduduk Indonesia tidak hanya mencakup sekedar makanan dan minuman saja, namun juga sudah merabah keproduk kosmetik (www.kompasiana.com, 2019)

Menurut Sumarwan,

(2011:209)

konsumen yang beragama Islam cenderung memilih produk yang dinyatakan halal dibandingkan dengan produk yang belum dinyatakan halal oleh lembaga berwenang. Kesadaran akan mengkonsumsi produk halal pada konsumen muslim, akibat dari pemahaman agama yang baik dan edukasi produsen mengenai sertifikat halal pada produknya. Hal ini akan berdampak semakin tingginya konsumen yang perduli tentang sertifikat label halal pada produk yang dibelinya, karena saat ini banyak konsumen yang semakin kritis dan memiliki pengetahuan produk yang baik sebelum melakukan keputusan pembelian.

Demikian juga dengan minat beli konsumen akan kosmetik, karena kosmetik telah bergeser dari perlengkapan menjadi kebutuhan bagi sebagian kalangan. Tidak jarang kosmetik menjadi kebutuhan primer dalam belanja bulanan. Wanita cendung membelanjakan uangnya lebih banyak untuk penampilan seperti pakaian, alat-alat perawatan, kecantikan rambut, dan sebagainya (Kasali,1998:34). Didukung oleh pendapat Belch \& Belch, (2001:159) kosmetik adalah salah satu pembelian yang menekankan keterlibatan perasaan (emosianal), sehingga terkadang figur atau tokoh idola yang menjadi brand ambassador pada suatu iklan kosmetik dapat menstimulan pembeli.

Selebriti adalah tokoh (aktor, penghibur atau atlet) yang dikenal masyarakat karena prestasinya didalam bidang-bidang yang berbeda dari golongan produk yang didukung. Selebriti secara definisi adalah orang-orang yang dikenal secara luas oleh masyarakat, baik itu seorang bintang film, penyanyi, atlet, maupun model. Seperti diketahui, iklan sebenarnya merupakan bentuk penyampaian pesan suatu merek kepada konsumen, seperti kosmetik dengan label halal dan citra religious tentu saja dibutuhkan selebriti yang memiliki personaldan kesan muslimah yang baik. Dalam hal ini kosmetik Wardah yang menjadi obyek penelitian menggunakan beberapa selebriti yang memiliki kesan religius seperti Dewi Sandra, Inneke Koesherawati, Lisa Namuri dan Dian Pelangi (Momzhak, 2015). Selebriti yang dipilih Wardah sebagai Endorser memiliki citra dan kesan diri yang dianggap mewakili nilai-nilai dari produk Wardah, sejauh ini menggunakan Celebrity Endorser dalam mengkampanyekan pesan dari kosmetik halal dianggap cukup berhasil. Ketika pesan iklan itu berhasil, maka konsumen akan mengasosiasikan kosmetik halal dengan Wardah pada benak mereka.

Natalia \& Pramadi, (2001) menyatakan bahwa kosmetik merupakan sarana yang digunakan wanita untuk mewujudkan bayangan dirinya seperti yang diinginkannya. Pertiwi, (2009:6) mengatakan bahwa wanita mempunyai kebiasaan mendengar atau membaca iklan, sehingga wanita lebih mudah dipengaruhi oleh iklan dan pada akhirnya akan mudah juga dipengaruhi minat membelinya. Shimp, (2003:374) menyatakan iklan dapat mempengaruhi pengharapan konsumen tentang suatu produk, dan menggerakkan untuk melakukan pembelian. Pembelian yang dilakukan konsumen termasuk dalam rantai keputusan pemebelian. Pada umumnya, proses keputusan pembelian yang dilakukan oleh seorang konsumen melalui lima tahap yaitu pengenalan masalah, pencarian informasi, evaluasi alternatif, pembelian dan perilaku pasca pembelian.

Konsumen dalam melakukan keputusan pembelian dapat dipengaruhi salah satunya oleh keterlibatan yang dirasakan oleh konsumen terhadap produk yang akan mereka beli. Pengaruh perasaan atau afeksi pada konsumen menjadi peluang bagi perusahaan untuk 
mempengaruhi proses keputusan pembelian mereka. Memanfaatkan keunggulan dari figur selebriti yang menginspirasi dengan segudang prestasi tentu saja memiliki dampak yang positif bagi produk yang dicitrakannya. Selebriti menarik perhatian dan membantu memperkenalkan produk kepada pelanggan, selebriti disukai oleh masyarakat umum mampu menarik recall yang lebih tinggi. Tugas utama Endorser adalah untuk menciptakan hubungan yang baik antara dirinya dan produk yang diiklankan sampai sikap positif yang dihasilkan terhdap konsumen dapat tercapai. Jika hal ini di kelola dengan baik oleh produsen dan endorser akan memberikan stimulasi pada konsumen, ini yang menjadi strategi pemasaran dalam mempengaruhi konsumen dalam melihat kesan yang ditimbulkan oleh endorser (Widyaningrum, 2016).

Kosmetik wardah memberikan jaminan kenyaman bagi konsumen melalui jaminan kehalalan produk kosmetiknya yang membantu konsumen memulai jaminan kehalalaan produk kosmetiknya yang membantu konsumen terhindar dari penggunaan bahan yang diragukan kehalalanya (Satyahadi, 2013). Tentunya kita tidak ingin melanggar apa yang telah disyariatkan oleh agama dalam mengkonsumsikan suatu produk sehingga membuat kita tidak nyaman dalam menggunakannya. Menurut Makmum, (2016) komitmen Wardah dalam menciptakan kosmetik halal diapresiasi oleh Euromonitor Internasional In Cosmetics Paris tahun 2016, kosmetik halal ini mendapatkan Global Fastest Growing Brand tahun 2014-2015 dengan rentang pertumbuhan (21\% - 100\% pertumbuhan).

Hubungan label halal dengan celebrity endorser serta keputusan pembelian adalah bagimana pemasar menciptakan produk yang halal dan bersignifikan sehingga konsumen muslim merasa terlindung untuk mengkonsumsinya, melalui media iklan akan disampaikan pesan iklan dari produk tersebut bahwa memiliki sertifikasi halal, membuat konsumen menyadari kebutuhannya akan produk, menggerakan minat mereka pada produk dan melakukan tindakan pembelian (Shimp 2003:385).

\section{STUDI LITERATUR}

\section{Label Halal}

Menurut Utami, (2013) adalah pencantuman tulisan atau pernyataan halal pada kemasan produk untuk menunjukkan bahwa produk yang dimaksud berstatus sebagai produk halal.

\section{Celebrity Endorser}

Menurut Leslie, (2011) mendefinisi celebrity endorser merupakan bagian penting dari suatu kampanye pemasaran produk. Harapan dari penggunaan celebrity endorsement adalah image atau kualitas selebriti akan berpindah terhadap produk dan merangsang penjualan. Menggunakan selebriti sebagai endorser memiliki keuntungan yaitu dari segi publisitas dan kemudahan mendapatkan perhatian dari calon konsumen. Seseorang yang sangat terkenal dapat digunakan untuk mengidentifikasi dan mengelompokan segmen yang yang besar dari target audience. Daya tarik dan nama baik dari seseorang selebriti dapat digunakan oleh pemasar untuk membentuk citra yang positif terhadap produk.

\section{Keputusan Pembelian}

Menurut Kotler \& Amstrong, (2012) proses keputusan pembelian adalah tahap dalam proses pengambilan keputusan pembeli di mana konsumen benar-benar membeli. Konsumen bebas memilih produk yang diinginkan sesuai dengan kebutuhannya, memutuskan tempat pembelian, bagaimana caranya, banyak pembelian, kapan membeli, dan mengapa harus membeli. Konsumen membeli dan mengkonsumsi produk bukan sekedar karena nilai fungsi awalnya, namun juga karena nilai sosial dan emosionalnya.

\section{KERANGKA KONSEPTUAL DAN HIPOTESIS PENELITIAN}

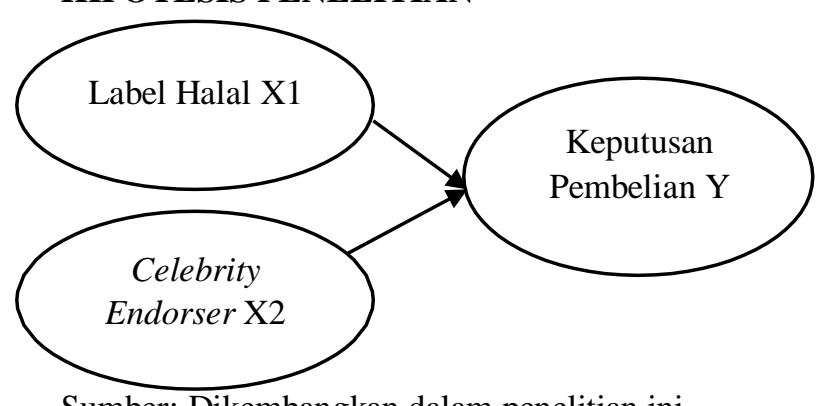

Sumber: Dikembangkan dalam penelitian ini,

2019

Gambar 2.2. Kerangka Konseptual

Keterangan :

$\longrightarrow$ : Pengaruh masing-masing variabel independen terhadap variabel dependen secara parsial. 


\section{HIPOTESIS}

digunakan nilai 0,5 dengan asumsi bahwa daftar

$\mathrm{H}_{1}$ : Label Halal Berpengaruh Positif dan Signifikan Terhadap Keputusan Pembelian.

$\mathrm{H}_{2}$ : Celebrity Endorser Berpengaruh Positif Terhadap Keputusan Pembelian.

\section{METODE PENELITIAN}

Penelitian ini merupakan penelitian yang menggunakan pendekatan metode kuantitatif. Pendekatan kuantitatif dapat diartikan sebagai metode penelitian yang digunakan untuk meneliti pada populasi atau sampel tertentu. Penelitian ini termasuk penelitian survei. Populasi dalam penelitian ini yaitu seluruh pelanggan kosmetik Wardah di kota Sumbawa. Sampel dari penelitian ini adalah bagian kecil dari karakteristik yang dimiliki oleh populasi tersebut. Metode penentuan sampel yang digunakan adalah purposive sampling yang dipilih berdasarkan kriteria-kriteria tertentu.

\section{Teknik Analisis Data}

Metode analisis data yang digunakan dalam penelitian ini adalah menggunakan uji instrumen penelitian, uji asumsi klasik, uji analisis regresi linier berganda dan uji hipotesis. Interpretasi hasil penelitian baik secara parsial melalui uji-t maupun secara simultan melalui uji-F. Alat analisis yang digunakan SPSS 16.

\section{HASIL DAN PEMBAHASAN}

\section{Hasil Uji Instrumen Penelitian}

\section{Uji Validitas}

Uji validitas dilakukan dengan membandingkan nilai $r_{\text {hitung }}$ dengan $r_{\text {tabel }}$ apabila $\mathrm{r}_{\text {hitung }}$ lebih besar dari $\mathrm{r}_{\text {tabel }}$ (pada taraf signifikansi 0.05), maka dapat dikatakan item kuesioner tersebut valid, tetapi jika $r_{\text {hitunglebih }}$ kecil dari $r_{\text {tabel }}$ maka butir pernyataan tersebut tidak valid. Penelitian ini menghasilkan nilai $r_{\text {hitung }}>$ dari pada $r_{\text {tabel }}$ sebesar 5,741 > 1,664 sehingga dapat disimpulkan bahwa semua instrumen dalam penelitian ini dapat dikatakan valid.

\section{Uji Reliabilitas}

Pengujian reliabilitas terhadap seluruh item atau pernyataan pada penelitian ini menggunakan rumus koefisien Cronbach Alpha. Nilai Cronbach Alpha pada penelitian ini akan 
pernyataan yang di uji akan di katakan reliabel bila nilai Cronbach Alpha $\geq 0,5$. Masing-masing variabel dalam Penelitian ini menghasilkan nilai Cronbach Alpha yang lebih besar dari 0,5 dimana nilainya sebesar 2,513>1,664. Kondisi ini menunjukan bahwa seluruh variabel tersebut adalah reliabel dan dapat digunakan pada analisis selanjutnya.

\section{Hasil Uji Asumsi Klasik}

\section{Uji Normalitas}

Uji normalitas pada penelitian ini menggunakan Kolmogorov Smirnov (K-S). Dalam uji ini apabila nilai sig < 0,05 maka data tidak terdistribusi dengan normal. Namun jika nilai sig > 0,05 maka data terdistribusi dengan normal. Hasil uji normalitas yang menggunakan metode Kolmogorov-Smirnov di dapatkan hasil signifikansi dari uji normalitas sebesar 0,580 dimana hasil tersebut lebih besar dari taraf signifikansi 0.05 , sehingga dapat disimpulkan bahwa uji normalitas pada penelitian ini adalah terdistribusi normal.

\section{Uji Multikolinearitas}

Ada tidaknya multikolinearitas dapat dilihat dari besarnya Variance Infalation Factor (VIF) dan nila Tolerance. Yaitu jika tolerance value $\leq$

0.10 atau VIF $\geq 0.10$ maka tidak terjadi multikolinearitas. dari hasil uji multikolinearitas yang dilakukan dalam penelitian menunjukan bahwa variabel Label Halal (X1) dengan nilai tolerance $0.805>0.10$ dan nilai VIF $1.243<10$, variabel Celebrity Endorser (X2) dengan nilai tolerance $0.805>0.10$ dan nilai VIF $1.234<10$. Maka dapat disimpulkan bahwa semua variabel bebas tidak terjadi multikolinearitas.

\section{Uji Heteroskedastisitas}

Berdasarkan hasil uji gelejser di dapat dilihat bahwa nilai signifikansi kedua variabel independen lebih dari 0,05peroleh nilai Variabel Label Halal memiliki signifikansi 0,10 dan variabel Celebrity Endorser memiliki nilai 0,259. Dengan demikian dapat disimpulkan bahwa tidak terjadi masalah heteroskedastisitas pada model regresi.

\section{Hasil Uji Analisis Regresi Linier Berganda}

Analisis regresi linier berganda pada penelitian ini di gunakan untuk mengetahui pengaruh Label Halal (X1), Celebrity Endorser (X2) terhadap keputusan pembelian (Y). Hasil persamaan regresi berganda adalah sebagai berikut:

a) Nilai konstanta (a) bernilai negatif sebesar 0,720 hal ini menunjukkan apabila variabel label halal dan celebrity endorser konstan, 
maka keputusan pembelian mengalami penurunan sebesar 0,720 .

b) Koefisien regresi variabel label halal X1 bernilai positif sebesar 0,638 ini menunjukkan bahwa variabel label halal bertambah 1 poin, sementara variabel independen lainnya tetap, maka keputusan pembelian akan mengalami peningkatan sebesar 0,638 dengan kata lain nilai koefisien regresi untuk variabel label halal bernilai positif menyatakan bahwa apabila semakin tinggi label halal maka semakin tinggi pula tingkat keputusan pembelian.

c) Koefisien regresi variabel celebrity endorser X2 bernilai positif sebesar 0,170 hal ini menunjukkan bahwa variabel celebrity Endorser ini menunjukkan bahwa variabel citra merek bertambah 1 poin, sementara variabel independen lainnya tetap, maka keputusan pembelian akan mengalami peningkatan sebesar 0,170 dengan kata lain nilai koefisien regresi untuk variabel celebrity endorser bernilai positif menyatakan bahwa apabila semakin tinggi citra merek maka semakin tinggi pula tingkat keputusan pembelian.

\section{Hasil Uji Hipotesis}

\section{Uji t (Uji Parsial)}

Uji t dalam penelitian ini menggunakan tingkat signifikansi 0.05 , jika nilai sig $>0.05$ maka Ho ditolak dan $\mathrm{Ha}$ diterima, sedangkan jika nilai sig $<0,05$ maka Ho diterima dan Ha ditolak.

Hipotesis 1: Label Halal Berpengaruh Positif dan Signifikan Terhadap Keputusan Pembelian.

Berdasarkan hasil uji $\mathrm{t}$ dapat dilihat bahwa nilai $t_{\text {hitung variabel kualitas produk }}$ sebesar 5.714, dimana $t_{\text {hitung }}>t_{\text {tabel }}(5.714>$ 1.664) dengan nilai signifikansi $0.000<$

0.05. Maka Ho ditolak dan Ha diterima, sehingga dapat di simpulkan bahwa terdapat hubungan positif dan signifikan antara label hakal dengan keputusan pembelian.

Hipotesis 2: Celebrity Endorser Berpengaruh Positif Terhadap Keputusan Pembelian.

Berdasarkan hasil uji $\mathrm{t}$ dapat dilihat bahwa nilai $t_{\text {hitung variabel harga sebesar }}$ 2.513 dimana $t_{\text {hitung }}>t_{\text {tabel }}(2.513<1.6644)$ dengan nilai signifikansi $0.14<0.05$. Maka Ho diterima dan Ha ditolak, sehingga dapat di simpulkan bahwa terdapat hubungan positif tetapi tidak signifikan antara harga dengan keputusan pembelian.
3. Koefisien Determinasi $\left(\mathrm{R}^{2}\right)$

Menunjukan bahwa nilai $\mathrm{R}$ square sebesar 0.398. Hasil ini membuktikan bahwa pengaruhLabel Halal, Celebrity Endorser, terhadap keputusan pembelian sebesar 38,6\% dan sisanya $61,4 \%$ di pengaruhi oleh faktorfaktor lain diluar variabel yang digunakan dalam penelitian ini.

\section{PEMBAHASAN}

\section{Pengaruh Label Halal Terhadap Keputusan Pembelian}

Berdasarkan hasil uji hipotesis menggunakan uji parsial (Uji t), yang telah dijelaskan di atas menunjukkan bahwa $\mathrm{H}_{\mathrm{a}}$ diterima, yang diketahui bahwa terdapat pengaruh positif secara signifikan antara label halal terhadap keputusan pembelian, yang berarti bahwa semakin tinggi kualitas produk kosmetik Wardah, maka keputusan pembelian kosmetik Wardah oleh konsumen juga akan semakin tinggi. Hal ini menunjukkan bahwa keputusan pembelian berpengaruh oleh label halal, dimana label halal menjadi pertimbangan dalam proses pengambilan keputusan dalam melakukan pembelian produk kosmetik Wardah di Kota Sumbawa.

Sebagian besar responden menjawab setuju dengan pernyataan bahwa label halal pada kemasan kosmetik wardah namfak jelas hal inilah yang menyebabkan konsumen memiliki kepercayaan atas label halal yang dapat menjamin produk dari produk haram.

\section{Pengaruh Celebrity Endorser Terhadap Keputusan Pembelian}

Berdasarkan hasil uji hipotesis menggunakan uji parsial (Uji t), telah dijelaskan di atas menunjukan bahwa Ha diterima, yang diketahui bahwa terdapat pengaruh positif secara signifikan Celebrity Endorser terhadap Keputusan Pembelian dapat diketahui bahwa Celebrity Endorser secara parsial berpengaruh positif dan signifikan terhadap Keputusan Pembelian terhadap pengguna kosmeti penelitian ini sejalan dengan penelitian wardah. Hal ini dapat dilihat dari jawaban respon den terbanyak yang menyatakan bahwa celebrity endorser dalam menyampaikan pesan sangat dapat dipercaya untuk mengenali suatu produk.

Oleh karena itu konsumen akan lebih memilih produk berdasarkan selebriti pendukung ketika mereka benar-benar tidak tahu tentang merek tersebut. Dengan terpilihnya Dewi Sandra sebagai endorser produk kosmetik wardah yang juga merupakan duta hijab 
indonesia dan penghargaan-penghargaan lain yang dicapainya sehingga dapat meyakinkan konsumen untuk menggunakan kosmetik wardah.

\section{PENUTUP}

\section{Kesimpulan}

1) Label Halal memberikan pengaruh yang positif dan signifikan terhadap keputusan pembelian padaproduk Kosmetik Wardah. Hal ini membuktikan bahwa keberadaan label halal pada produk kosmetik memberikan nilai positif yang memiliki peluang besar dalam mempengaruhi keputusan pembekian konsumen. Keputusan pembelian diambil dari persepsi terlebih dahulu dimana orang akan memilih, mengatur dan mempertimbang kan produkproduk yang akan dikonsumsi.

2) Celebrity Endorser memberikan pengaruh yang positif tetapi tidak signifikan terhadap keputusan pembelian pada Kosmetik Wardah. Hal ini membuktikan bahwa Celebrity Endorser memberikan nilai positif dan dapat dipercaya pada keputusan pembelian dalam mengiklankan produk kosmetik tersebut.

\section{Saran}

1) Bagi perusahaan,

Bagi produsen kosmetik Wardah, disarankan untutk tetap memelihara kualitas pelayanan terhadap konsumen dengan memperhatikan segala aspek bukan hanya dengan Label Halal maupun Celebrity Endorser. Konsumen yang merasa puas terhadap produk kosmetik Wardah akan menjamin konsumen tetap produk itu sendiri, dan tidak akan berpindah ke produk kosmetik lainnya.

2) Bagi penelitian ini diharapkan dapat dijadikan referensi untuk penelitian selanjutnya. Penelitian ini masih memiliki banyak kekurangan. Peneliti selanjutnya dapat menambahkan variabel bebas lainnya yang dapat memberikan pengaruh pada keputusan pembelian sehingga mampu memberikan hasil penelitian yang lebih baik lagi.

\section{DAFTAR PUSTAKA}

Adi Sasminto, dan Wiku, (2010). Analisis Kebijakan Nasional MUI dan BOPM dalam Labeling Obat dan Makanan. Jurnal Kebijakan Nasional MUI dan
BOPM Fakultas Kesehatan Masyarakat Universitas Indonesia.

Belch, Greorge E. \& Michael A. Belch. (2001). Introduction And Promotion. An Integrated Marketing. McGraw Hill Company.

Bps,(2016).jumlahpenduduksumbawakab,http:// www.sumbawakab.bps.go.id(diakses 15 juni 2018).

Bps,(2010).jumlah penduduk persentase menurut agama Indonesia. http://www.tumoutonews.com diakses 8 november 2018.

Burhanuddin. (2011).Pemikiran Hukum Perlindungan Konsumen dan Sertifikat Halal (140,p.142), Universitas Negeri Maaulana Malik Ibrahim Maliki Press. Malang.

Ghozali, Imam. (2016)."Aplikasi Analisis Multivariate dengan program IBM SPSS 23" Badan Penerbit Universitas Di Ponegoro, Semarang, 2016.

Kementerian Agama RI. Al-qur'an dan terjemahan. Jakarta :Mumtaaz Media Islami, 2010

Kompasiana. (2016). Sistem jaminan produk halal indonesia antara kebutuhan dan tantangan https://www.kompasiana.com. diakses 19 Desember 2016

Kotler, Philip dan Amstrong. (2010). Princeples Of Marketing. Edisi 13. Engldan : Pearson.

Kotler, Philip dan Amstrong. (2012).Marketing Management New Jersey : Person Pretice Hall.

Kotler, Philip dan Keller. (2013).Marketing Management. Edisi 14. Engldan : Pearson.

Leslie, Larry Z. (2011). Celebrity in 21th Century. ABC-CLIO, LCC. California.

LPOM MUI. (2017). Sertifikasi Halal MUI.www.halalmui.org. (diakses 7 desember 2018).

LPPOM MUI. (2019). Sertifikasi Halal MUI.www.halalmui.org. (diakses 8 februai 2019).

Momzhak.(2015).Http://www.halabea.com/201 5/10/ daftar kosmetik halal terlengkap 2015.html, diakses 10 mei 2016.

Natalia \& Pramadi. (2001). Daya tarik fisik, Online:http//www.wikipedia.com. diakses 2 Maret 2010.

PT. Paragon and Innovation. http://www.paragoninnovation.com/brand/wardah 
diakses 19 desember 2015 . 
Priyanto, D. (2016). "SPSS Handbook: Analisis Data, Olah Data, \& Penyelsaian Kasu-Kasus Statistik", Yogyakarta Mediakom, 2016.

Priyanto, Duwi. (2012). Cara Kilat BelajarAnalisis Data dengan SPSS 20, Yogyakarta, Media Kom, Penerbit Andi.

Republik Indonesia. (1997). Peraturan Pemerintah Nomor 69 Tahun 1999 Tentang Label dan Iklan Pangan, Lembaga Negara RI Tahun 1999, No. 131. Sekretariat Negara. Jakarta.

Republik Indonesia. (2014). Keputusan Menteri Undang-Undang Nomor 33 Tentang Jaminan Produk Halal Negara RI.

Satyahadi, Alfread. (2013). http: // www. Indonesiaprintmedia.com/ pendapat/ 225-pentinya-penggunaan-labelpada-kemasan.html, diakses $10 \mathrm{mei}$ 2016.

SharianNews.(2017). Potensi pasar kosmetik diIndonesia.http://www.Halal MUI.Sharian newws.com diakses 7 desember 2018

Shimp, Terence A. (2014). (terj. Haryi.” Bhima Sena, Fitrisanti, Anisa PuspitaDewi)."Komunikasi Pemasaran Terpadu Dalam Periklanan dan Promosi", Edisi 8.Jakarta : SelambaEmpat, 2014.

SindoNews.(2019). Pertumbuhan permintaan produk halal dunia. http://www.sindownews.com diakses februari 2019.
Stanton, Wiliam J dan Matt Hew AGana. (2008).Principless Of Maeketing. (EBOOK) tersedia http://www.nou.edu.rig//NOUN_OC L/pdf/pdf2/BMH\%20206.pdf (diakses pada 17 April 2017).

Sugiyono. (2017)."Statistika untuk Penelitian", Penerbit Alfabeta, 2017.

Sugiyono. (2010). "Metode penelitian Kuantitatif, Kualitatif $R \& D$,, Bandung: Alfabeta.

Sugiyono. (2014)."Metode penelitian Kuantitatif Kualitatif dan R\&D”, Penerbit: Alfabeta, 2014.

Sunyanto, Danang. (2013).Metodelogi Penelitian Akuntansi.Bandung : PT RefikaAditamaAnggotaIkapi.

Ujang, Sumarwan. (2011). Prilaku Konsumen: teori dan penerapan dalam pemasaran. Ghalia Indonesia. Bandung.

Utami, Wahyu Budi. (2013)."Pengaruh Label Halal Terhadap Keputusan Pembelian (Survei Pembelian Kosmetik Wardah Dioutlet Wardah Griya Muslim AnNisa Yogyakarta)". Skripsi, Yogyakarta Fakultas IlmuSosial dan Hubungan Humanioris Universitas Islam Negeri Sunan Kalijaga Yogyakarta.

Widya, Ningrum, Premi. (2018). Pengaruh Label Halal, Asosiasi Merek, Iklan, dan Celebrity Endorser terhadap Keputusan Pembelian (Survei Pada Konsumen Wardah Kota Malang). 